\title{
SOMA: an organic and autonomous approach to manufacturing planning and control
}

\author{
A. A. Queiroz, Ph.D. and H. A. Lepikson, M.Eng. \\ UFSC/GRUCON-Federal University at Santa Catarina State, \\ Research Group on Numerical Control and Industrial Automation \\ Address: UFSC/EMC/GRUCON \\ 88040-900, Florianopolis-SC, Brazil \\ Phone: +55-48-3319387 Fax: +55-48-2341519 \\ E-Mail: hal@grucon.ufsc.br
}

\begin{abstract}
The complexity of manufacturing systems overload their structure and impose hard conditions for their routine operation. This paper first analyses this problem and proposes a new approach for planning and operating manufacturing systems, based on the dynamic aggregation of autonomous manufacturing units working in a co-operative, negotiated way based on the attendance of the present and prospective market needs. Then it sets out a system architecture and introduces a methodology for the shop floor planning and control which is capable both of meeting the objectives and constraints of these autonomous units with enhanced synergy and of keeping the system's integrity.
\end{abstract}

Keywords
Distributed manufacturing, shop floor planning and control

\section{INTRODUCTION}

Today organisations tend to become more and more sophisticated so as to cope with the challenge of the frequent change to attend market demands, including the introduction of new products. Complexity is a problem faced by the companies on every organisational level, with particular and important consequences for the workshop structure. 
Complexity imposed on the big companies lacks agility and, to the small ones, lacks capital as well as technological and managerial support to play the game in this new and competitive arena, as observed by Fernandes (1995) and Hamel (1994). Complexity also brings an enormous struggle to the manufacturing system, since constancy, discipline and learning with experience are important for its performance. Operation of manufacturing routines is highly sensitive to disturbances, due to interwoven flows of material and information that lead to mutual dependence on resources. As a consequence, the planning and operation of the manufacturing system is truly a hard task. Scheduling, for instance, is often obsolete even before it is about to be carried out. Rescheduling comes to be more the rule than the exception.

The traditional approach to solve these problems is based on the deploying functions in a hierarchically way in order to divide big issues into smaller ones, that are easier to deal with. (See, for instance, Scheer, 1993 or Williams, 1989). The culture of the company is structured by this way of thinking, and, by extension, so are management issues, personnel training, software development, resource planning, and so on. This has been historically a valid concept, inherited from Taylor's postulates, with the following main characteristics (Bullinger, 1993):

- separation between planning and execution activities;

- hierarchical, centralised, management and control;

- organisation by functions (e.g., design, dispatching, assembly functions).

As long as the manufacturing companies have evolved, this concept has led to a more and more complex decision structure, with numerous interfaces and relations and, as a consequence, with a greater struggle for co-ordination and control of resources. The results of research on manufacturing that has sought to understand and deal with this complexity have shown that it can be a very hard work, and not always successful (e.g., Bienert, 1993).

This present reality brings new threats, but also new opportunities. Among the threats, the exponential growth in complexity and awkward relations with the market deserve special attention. On the other hand, among the opportunities, there are the technical and organisational resources potentially able to help in managing the situation, such as the optimum qualification of human resources, the sophistication of information systems and the flexibility achieved by new equipment.

To successfully take advantage of this situation, companies must rethink their vision of business, their strategy and, as a consequence, their way of planning the manufacturing process. The approach here proposed is an attempt to help industries plan their workshop in this direction and to simplify their manufacturing structures. It is based on the concept of Autonomous Units working with high synergy (organicity). First, the concept and its architecture are introduced. Then the paper addresses the mechanisms which make the concept possible in the particular case of manufacturing planning and control.

\section{THE ORGANIC AUTONOMOUS APPROACH}

The Organic Autonomous Approach, called here SOMA (an acronym for the Portuguese translation of Organic Autonomous Manufacturing System, which is Sistema Orgânico de Manufatura Autônoma) is somewhere between the traditional, hierarchical and centralised way of thinking and the new research towards fully decentralised structures (see, for instance, 
Mathews, 1995, Tharumarajah, 1996, Ueda, 1994, Warnecke,1993). SOMA is particularly fitted to repetitive manufacturing kind of industries which, at the same time, frequently need to introduce new products.

Compared with the hierarchical organisation (figure 1), the SOMA Approach breaks with the traditional manufacturing paradigms. In this sense, its main characteristics are:

- aggregation of planning and execution in focused, independent, units;

- decentralised management and control, mainly supported by negotiation strategies;

- organisation by process (manufacturing process, maintenance process, etc.).

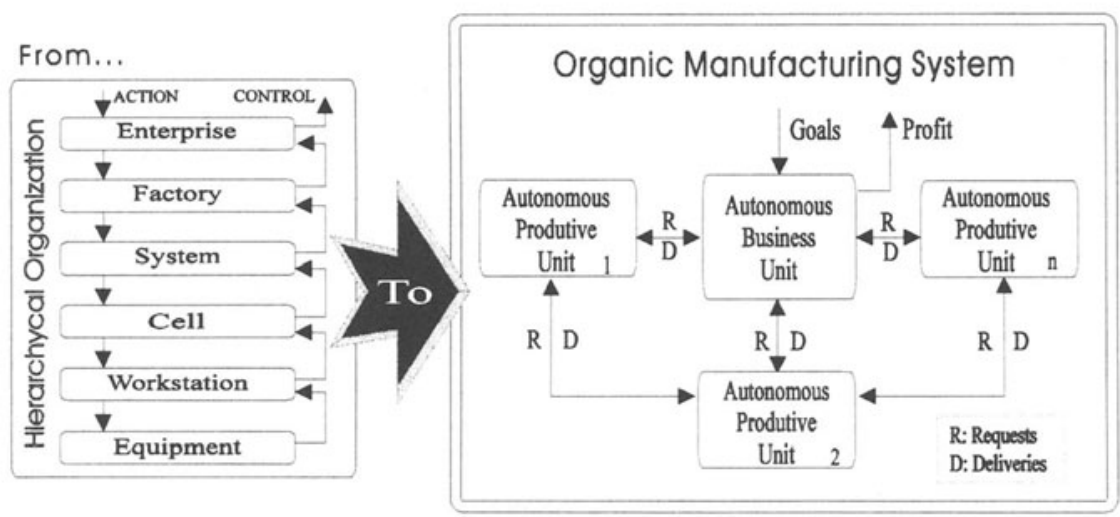

Figure 1 Comparison between traditional and Autonomous approach to manufacturing organisation.

On the other hand, compared with the fully decentralised systems, the main differences are twofold: first, the Autonomous Approach does not set out to build a fully decentralised system from the machine level on. Although this could be done, by concept it is transparent to the system. SOMA envisages the Unit as its smallest and only instance to be managed. Second, it does not pursue a totally automated control system. Instead, it takes advantage of the human skill, capacity of judgement and experience to give leverage to the competencies on each Unit and, by means of co-operation and negotiation among them, to also provide leverage for the whole system.

The AUs are focused on product. Hence, they have only one mainstream process to maintain and develop. This means that every Autonomous Unit (AU) has a very clear view regarding which core competencies they must pursue and, as a consequence, the strengths and weaknesses related to this competencies that they are to deal with in order to enhance their competitiveness and, in the end, their prospective "market share" (it must be previously understood that every AU sells most of its products to its preferential clients - probably another AU - and that its price and quality are under constant evaluation by benchmarking comparison). Focus on product also helps to organise the AUs by process: material, resources and information flow are co-ordinated by process objectives. 
The basic architecture of SOMA is based on two kinds of AUs: The Autonomous Business Unit (ABU) and the Autonomous Production Unit (APU). An ABU is mainly market-oriented. It has the responsibility of observing, analysing, and acting according to the prospective market desire. Figure 2 illustrates how SOMA works, observed by the information flow perspective.

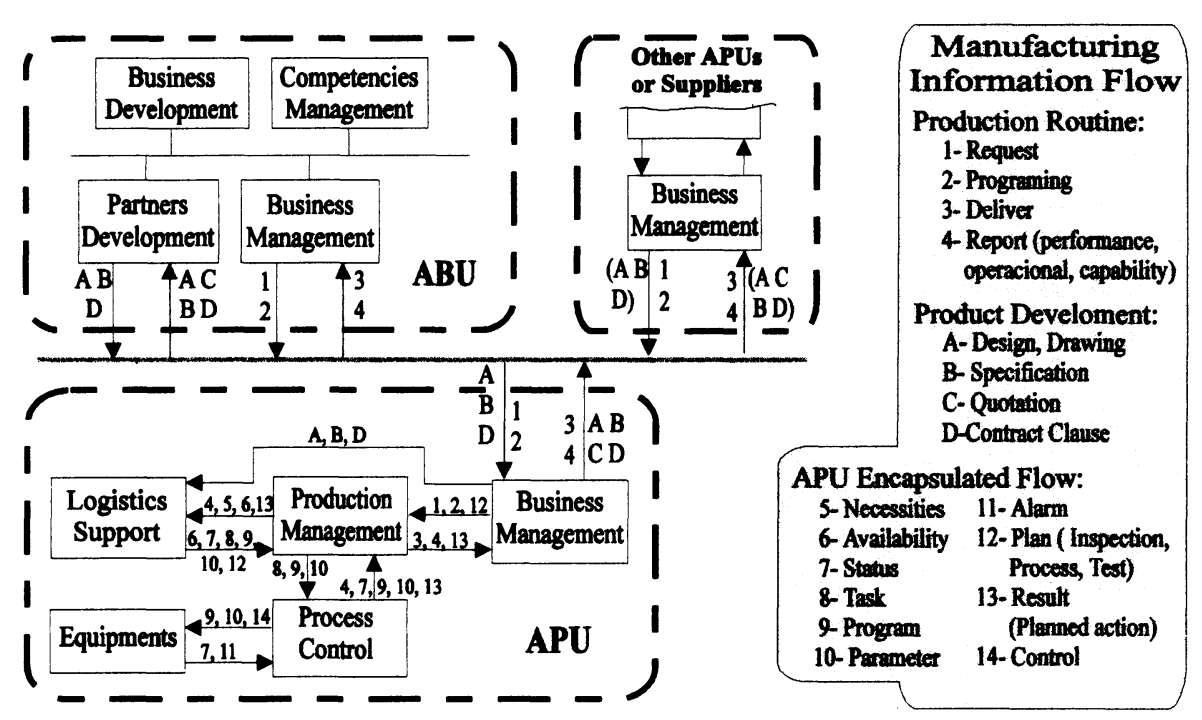

Figure 2 Basic architecture and the information flow on the Autonomous Manufacturing.

There is one ABU for each group of focused core competence. This is an important characteristic, for competencies are not always directly related to only one family of products. It is assumed that, in the long run, competitiveness derives from the ability to build these competencies. They, in turn, may generate unanticipated products to attend these prospective market desires (Prahalad, 1990) The ABU clearly assumes, in this sense, a differentiation strategy under Porters' perspective. But, on the short term basis, it also gives special attention to costs, since it is based on negotiation to operate with the APUs. This possibility partially solves a contradiction in Porters' strategy model (where cost and differentiation are excluding strategies) and comes nearer the perspective of building synergy by mutual compromise between quality and cost, as analysed by Corsten, 1993 and Fernandes, 1995.

The interface between ABU and APUs is oriented by the Business Management Module (BMM), which is similar, to the communication viewpoint, at every Unit (figure 2). BMM coordinates the supply chain by request-deliver derived functions. This means that ABU translates market needs into requests and orders for products and their related parts, assembly and services among AUs. To cope with this task, BMM must have a complete register of suppliers (mainly APUs) and their scope of competence. The functionality of the system will be explained in advance. At the ABU, BMM is supported by the Partners Development Module (PDM) in the activities aimed at the development of new products or new partners. PDM is necessary because of its long term perspective, quite different from the routine relation on a 
day-by-day basis to the existing products which are manufactured. PDP also has the important mission of managing and articulating product know-how from the organisation standpoint (which is not necessarily the same as product parts know-how, which are under APUs dominion).

Despite the importance of PDM, its functions are beyond the objectives of this paper, which is focused mainly on the APUs management and its relation to the whole system.

It is important observe that APUs are conceived as internal suppliers within a company. However, due to the SOMA approach, there is no hindrance to external suppliers when the situation calls for them. Additionally, the system can be potentially fitted for Virtual or Extended Enterprise compositions (NIST, 1994 and Browne, 1995).

APUs have a strong interrelation, since they are recognised and specialised by their core competencies. Hence, they are stimulated to develop alternative capacities and "markets" (i.e., new product ranges) within their core competencies to better occupy their resources. It is not important for the system to know how each APU works. As it can be seen in figure 2, the realtime control activities are totally encapsulated within the APU. The Partners Manager Module is the only one which has any relation with the outside world, considering the APU. This is a very useful characteristic, since the system can support working together AUs with different abilities or level of automation. Hence, this paper will focus on the relations between the AUs.

Two kinds of APUs may be distinguished: Product mainstream APU and Service APU. The first is directly dedicated to product manufacturing or assembling. The second is focused on specialised services to support production. Maintenance, testing and inspection, tooling, quality assurance, transport and handling or NC programming are some examples.

There could exist a third kind of APU, though it is not directly related to production. It is oriented to general services necessary within the organisation, such as accounting, finances, training, as well as juridical and other services. They are not considered here as APUs, since they are out of production scope. Nevertheless, nothing hinders them from being treated as APUs which sell services to other APUs/ABU, and using the same request-deliver functions. This extension of the approach simplifies cost management, since it allows the use of the same basic accounting functions to balance incomes and expenses among APUs as well as between APUs and ABU. This alternative strongly simplifies the manufacturing cost account, a problem still unsolved today (see, for example, Harmon).

APUs are managed like small enterprises. They extend the concept of cellular manufacturing to provide the necessary flexibility in size, lay-out, resources and even profits (in this case, the final result of primary performance measurements). The limit for its growth is defined by the Unit's self-management capacity. As a reference, the team should not exceed 15 people. This is necessary to keep the APUs' agility and focus. On the other hand, it is also important to maintain the mutual dependence and equilibrium among APUs.

\section{3}

\section{THE SOMA MANAGEMENT AND CONTROL SYSTEM}

SOMA management and control in the Autonomous Unit concept is based upon two keywords: negotiation (among units) and encapsulation (inside each unit). This means that control exists only inside each AU. And, among AUs, only requests and delivery-derived functions are sufficient to maintain the defined client-vendor relation (figure 1). The objective is to assure 
complete modularization of the manufacturing structure (which also has consequences in standardisation).

Figure 3 gives an overview of the concept. Negotiation is based on request-deliver functions which are applied through messages to objects which, then, internally invoke the necessary operations. When necessary, the invoked object returns (delivers) an answer. Figure 2 introduces some of the most important functions and where they apply.

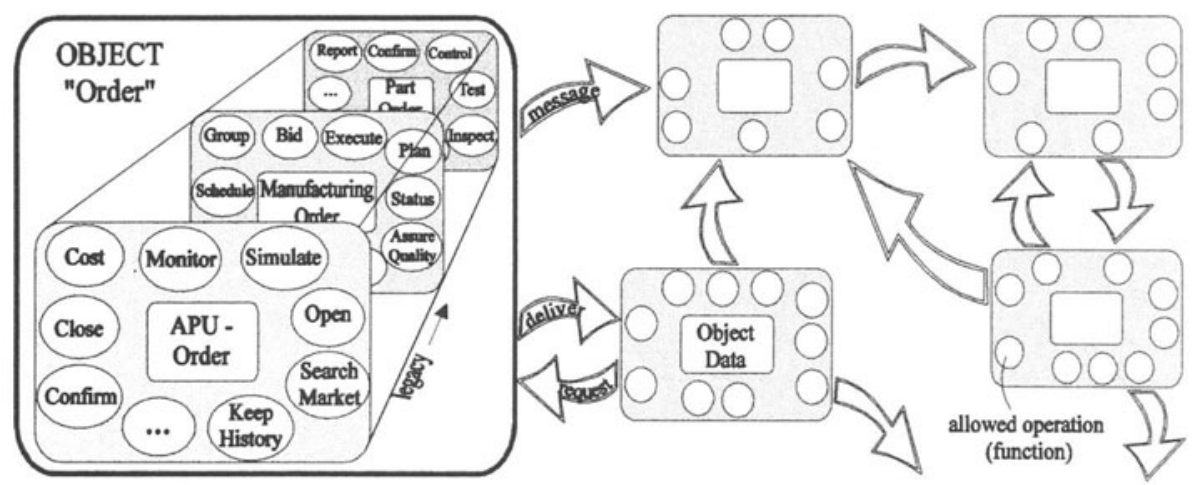

Figure 3 Control encapsulation and negotiation flow between objects.

Functions are assynchronically managed, which means that no control actions are involved. An object is any entity about which information must be manipulated and stored, including its manipulation methods. Objects (for instance, a manufacturing order for a specific part) are instances of object types (orders in the example). In this sense, a manufacturing order, a service order or an assembly order are all sub-objects of object Order. They inherit the properties and methods of the type order and add others, specific to their necessities (Martin)

Encapsulation is the consequence of hiding from the users details of how objects are manipulated. Its extended meaning makes it possible to shelter control actions within the AUs. In this context, AUs can be seen as object types which enclose sub-objects such as people, machines, software, tools, inventories, clients, suppliers, accounting, capability and so on.

As it can be noted, internal management and control are concealed from the external system (the AUs are objects themselves). This characteristic permits each AU to develop its own culture and personality, just like any enterprise. This brings enormous advantages to the SOMA concept, even when compared with the other decentralised approaches.

This characteristic also brings organicity to the system and imposes a common behaviour on every $\mathrm{AU}$ that is:

- market-driven, including:

$\checkmark$ performance concern;

$\checkmark$ inherent benchmarking with partners and competitors (which can be similar to AUs);

$\checkmark$ product life cycle attendance;

$\checkmark$ costumer audits; 
- product-driven, by the capacity of:

$\checkmark$ continuous tuning in to the costumer needs;

$\checkmark$ fast flaw correction;

$\checkmark$ continuous quality, cost and lead time evolution;

$\checkmark$ fast response to new product development;

- process-driven, since it is able to:

$\checkmark$ to be in tune with the minor changes or evolution of the market;

$\checkmark$ rapidly take advantage of the experience curve;

$\checkmark$ be sensitive to changes in capacity or capability when demanded by the market.

\section{THE UNIT PLANNING AND CONTROL SYSTEM}

Considering its smooth flow and the partnership built gradually, APUs can be co-ordinated in a kanban-like style, with some concessions to the Soma's specificity. From the organisational viewpoint, the APUs have a structure similar to Flexible Manufacturing Cells (as defined by Lepikson: product-driven and with self-control capacity), with three important differences:

- local planning and management capacity;

- free decision about resource allocation and opportunity use to advantage;

- APUs are supposed to address and manage the resources by themselves (including information and people) to accomplish their products.

As already stated, the relations between AUs are based on negotiation mechanisms. The system management and control is based on a reward-penalty system, oriented by market values. This concept adapts, for this scheduling purpose, the similar alternatives presented and tested by Márkus, 1996 and Iwata, 1994. It works as follows:

1. ABUs keep a performance portfolio of the other ABUs and APUs with which they maintain a close relation (besides their capacity to access other AUs within the SOMA).

2. When an $A B U$ starts negotiation of a new feasible order, it is technically and commercially evaluated as a whole and, when necessary, in every critical sub-product (parts of the product).

3. The product is then exploded into its sub-products and a call for tenders is placed for them among the APUs, including its specifications, process plans, drawings and so forth. It also includes the due date, the reward which $\mathrm{ABU}$ is ready to pay and the anticipated penalties for quality and delay problems.

4. APUs which are somehow interested in the business, negotiate the tender contents with $\mathrm{ABU}$ and then formally answer with a standard-format bid, with the reward and penalties they accept.

5. The ABU evaluates the best alternatives and places the orders (always in standard-format). It is considered for evaluation, along with the proposed revenues, the reliability index of the proponents (translated from their ranking on the reward-penalty board, which is also used for wage and profit share among the units).

6. If any invitation is not answered after the specified time, it is interpreted that the subproduct is it too risky for the anticipated reward. The ABU then reassesses its technical and commercial conditions and places another invitation for a tender, in newer basis. This is a 
simple and effective filter for the manufacture against those unfeasible designs, with the additional advantage of stimulating partnership from the earliest product development stages (to prevent those unfeasible designs).

7. APUs process the orders and deliver according the plan, while ABU applies rewards and penalties as contracted.

8. The ranking is continuously updated on the reward-penalty board and then published among the AUs.

Its worth noting that this process takes place for every new product that is to be introduced by SOMA or in any exceptional case (e.g., a reliability problems in an APU). Once the product is introduced and the AUs are already tuned in, the ABU converts the process into a pull order system, based on electronic kanbans, in the place of the tender invitation. APUs then will proceed to improve their position in the ranking, and, as a consequence, their revenue. Enhancement in productivity brings increase in capacity and a new interest in applying it by looking for new tender calls. On the other hand, AUs which are low-ranking will deserve special attention because they probably will fit into one of the three situations:

- they are overloaded, which is an opportunity for enhancement or duplication;

- they are inefficient (opportunity for improvement);

- they are frequently running idle (opportunity for deactivation).

This concept also brings some other interesting characteristics:

- When an urgent order (or special opportunity) comes to SOMA, it may stimulate fast reaction of the system by simply raising the rewards and the penalties according to the necessity;

- it is supported on highly modularised and standardised patterns, which allows, for example, an APU to use the same approach to search for partners to complement resources or competencies towards competing for a new product;

- it unifies most of the productivity measurements and greatly simplifies the system management;

- it makes it possible to optimise the system for short and long terms simultaneously, without losing any of the perspectives

\section{CONCLUSION}

The Autonomous approach focuses on the modularization of the manufacturing system. This brings the manufacturing planning and control problem to a manageable size and introduces new perspectives. The main aspects to highlight are:

- the capacity to deal with the current technologies and concepts (JIT, kanban, MRP, TQC, etc.) and to gradually migrate to others without cultural breakage;

- the inherent characteristic to protect itself from the tendency to introduce complicated, hierarchical management and control tools;

- the ease in expanding or reconfiguring manufacturing system;

- business orientation, high level of individual responsibility and quality understanding;

- clear identification and separation of value- and non-value-added activities; 
- transparency: traditional puzzle-like problem solving, such as hindered inventories, bottlenecks or production inefficiency are exposed before everybody's eyes;

- the use of the same primary performance measurement indicators to evaluate (with the same "currency") the various productive units of the enterprise.

Another aspect to pinpoint: in the Autonomous approach small and medium enterprises have the same opportunity to compete as the big ones. They have the opportunity to put together the competence and resources that they need in many different ways and with great flexibility and agility. This assures them a new competitive advantage even in an environment which favours concentration by capital capacity.

The concept embedded in the SOMA is now under test by simulation tools to evaluate its feasibility. The first results are encouraging. It is also planned to handle further tests with a real system in a medium size manufacturing company which currently works in a MRP-like style. Another test is planned in a JIT environment. The objective of these tests is to compare the SOMA performance against these two more traditional systems.

\section{REFERENCES}

Bienert, A. Schönenberger, D. (1993) Computer Aided Enterprise Modeling - A Global Approach, in Proceedings of. Advances in Production Management Systems (B-13), Elsevier, 323-30.

Browne, J. (1995) The Extended Enterprise Manufacturing and the Value Chain, in Proceedings of IEEE/ECLA/IFIP BASYS'95, Chapman \& Hall,. 05-16.

Bullinger, H. J. et al (1993) Integrated Management: How to Combine Lean Production and CIM in Proceedings. of 2nd International. Conference on Computer Integrated Manufacturing, Singapore.

Corsten, H. Will, T. (1993) Simultaneous Achievement of Cost Leadership and Differentiation by Strategic Production Organization, in. Proceedings of Advances in Production Management Systems (B-13), Elsevier, 47-55.

Fernandes, D. Lepikson, H. A. (1995) Product Differentiation as Basis for Competitive Strategy, in Proceedings of. 11th ISPE/IEE/IFAC CARS \& FOF'95 International Conference, Pereira, Colombia, 562-67.

Hamel, G. Prahalad, C K (1994) Competindo pelo Futuro. Ed. Campus, Rio de Janeiro.

Harmon, R L. Peterson, L D. (1991) Reinventando a Fábrica. Ed. Campus, Rio de Janeiro.

Iwata, K. Onosato, M. (1994) Random Manufacturing System: A New Concept of Manufacturing Systems for Production to Order, Annals of the CIRP, 43 (1), 379-383.

Lepikson, H.A. (1990) Padronização e Interação das Unidades de Fabricação, Manipulação e Inspeção de uma Célula Flexível de Manufatura. Universidade Federal de Santa Catarina, Dissertação de Mestrado.

Márkus, A. Váncza, T.K. Monostori, L. (1996) A Market Approach to Holonic Manufacturing, Annals of the CIRP, 45 (1), 433-36.

Martin, J. Odell, J.J. (1996) Análise e Projeto Orientados a Objeto. Makron Books, Rio de Janeiro. 
Mathews, J. (1995) Organizational Foundations of Intelligent Manufacturing Systems - The Holonic Viewpoint, Computer Integrated manufacturing Systems, 8 (4) 237-43.

NIST (1994) Workshop on Virtual Enterprise, Ann Arbor, MI, March 29-30, NIST- National Institute of Standards and Technology, Gaithersburg, MD.

Porter, M. E. (1991) Estratégia Competitiva. Ed. Campus, Rio de Janeiro.

Prahalad, C.K. Hamel, G. (1990) The Core Competence of the Corporation, Harvard Business Review, May-June, 79-91.

Scheer, A.-W. Jost, W. (1993) Knowledge-Based Optimization of CIM-Systems Using Industry Specific Reference Models, in Proceedings on Advances in Production Management Systems (B-13), Elsevier, 21-28.

Tharumarajah, A. Wells, A.J. Nemes, L. (1996) Comparison of the Bionic, Fractal and Holonic Manufacturing System Concepts, International Journal of Computer Integrated Manufacturing, 9, (3), 217-26.

Ueda, K. (1994) Biological-Oriented Paradigm for Artifactual Systems, Japan-USA Symposium on Flexible Automation- A Pacific Rim Conference, 1263-66, July 11-18.

Warnecke, H.-J. (1993) The Fractal Company, Springer-Verlag, Berlin.

Williams, T.J. (1989) A Reference Model for Computer Integrated Manufacturing. ISAInstrumentation Society of America / Purdue Research Foundation.

\section{BIOGRAPHIES}

Abelardo Alves de Queiroz, Ph.D.: Senior Professor at UFSC - Universidade Federal de Santa Catarina (Federal University at Santa Catarina State), Department of Mechanical Engineering. Responsible, for the manufacturing strategies research subgroup at the GRUCON - Research Group on Numerical Control and Industrial Automation. At the present, he is also Head of the Graduate Programs in Mechanical Engineering. Areas of interest: manufacturing strategies, manufacturing logistics, operation management.

Herman Augusto Lepikson, M.Eng.: Assistant Professor at UFBA - Universidade Federal da Bahia (Federal University at Bahia State), Department of Mechanical Engineering. At the present, joining the GRUCON - Research Group on Numerical Control and Industrial Automation in the UFSC for the studies and research towards his Doctorate degree. Areas of interest: manufacturing logistics, shop floor management and control. 